NASA Technical Memorandum 106364

189380

AIAA-93-4322

\title{
Mixing Noise Reduction for Rectangular Supersonic Jets by Nozzle Shaping and Induced Screech Mixing
}

Edward J. Rice

National Aeronautics and Space Administration

Lewis Research Center

Cleveland, Ohio

and

Ganesh Raman

Sverdrup Technology, Inc.

Lewis Research Center Group

Brook Park, Ohio

Prepared for the

15th AIAA Aeroacoustics Conference

sponsored by the American Institute of Aeronautics and Astronautics Long Beach, California, October 25-27, 1993

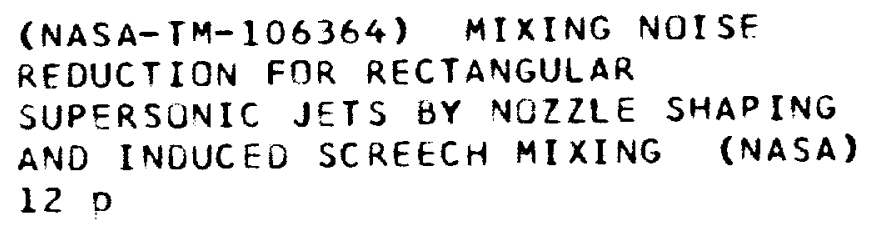


$-$ 


\title{
MIXING NOISE REDUCTION FOR RECTANGULAR SUPERSONIC JETS BY NOZZLE SHAPING AND INDUCED SCREECH MIXING
}

by

\author{
Edward J. Rice* \\ National Aeronautics and Space Administration \\ Lewis Research Center \\ Cleveland, Ohio 44135
}

and

\author{
Ganesh Raman** \\ Sverdrup Technology Inc. \\ NASA Lewis Research Center Group \\ Cleveland, Ohio 44135
}

\begin{abstract}
$\underline{\text { Abstract }}$
Two methods of mixing noise modification were studied for supersonic jets flowing from rectangular nozzles with an aspect ratio of about five and a small dimension of about $1.4 \mathrm{~cm}$. The first involves nozzle geometry variation using either single (unsymmetrical) or double bevelled (symmetrical) thirty degree cutbacks of the nozzle exit. Both converging (C) and convergingdiverging (C-D) versions were tested. The double bevelled $C-D$ nozzle produced a jet mixing noise reduction of about $4 \mathrm{~dB}$ compared to a standard rectangular C-D nozzle. In addition all bevelled nozzles produced an upstream shift in peak mixing noise which is conducive to improved attenuation when the nozzle is used in an acoustically treated duct. A large increase in high frequency noise also occurred near the plane of the nozzle exit. Because of near normal incidence, this noise can be easily attenuated with wall treatment. The second approach uses paddles inserted on the edge of the two sides of the jet to induce screech and greatly enhance the jet mixing. Although screech and mixing noise levels are increased, the enhanced mixing moves the source locations upstream and may make an enclosed system more amenable to noise reduction using wall acoustic treatment.
\end{abstract}

\section{$\underline{\text { Introduction }}$}

The objective of this research is to study ways in which the noise of a supersonic rectangular jet can be significantly reduced using excitation or other shear flow control means which could find practical application in a

\footnotetext{
*Lewis Distinguished Research Associate, retired, Member AIAA

**Research Engineer
}

Copyright (C) 1993 by the American Institute of Aeronautics and Astronautics, Inc. No copyright is asserted in the United States under Title 17, U.S. Code. The U.S. Government has a royalty-free license to exercise all rights under the copyright claimed herein for Governmental purposes.

All other rights are reserved by the copyright owner. single or multiple jet mixer or ejector device. It is intended that this excitation device be a natural source which feeds upon the steady flow for its energy rather than requiring an external power source of any kind. The emphasis of this work was to investigate geometries which would be used internal to a shroud and this has led to the concentration on near-field hydrodynamic and acoustic fields. Two approaches to improving the performance of such devices seem obvious. The first is to cause the directivity of the internally generated mixing noise to be more normal to the acoustic treatment surface which would make the suppressor much more effective. An attempt to accomplish this first objective led to the double-beveled nozzle tests which are reported here. In some, but not all cases, the directivity was significantly changed for the mixing noise frequencies of interest, and the jet noise was reduced significantly. Thus the bevelled nozzle may be a candidate for the internal mixer-ejectors where properly designed acoustic treatment might be used to further exploit the directivity changes. The second approach is to increase the mixing rate of the jets to move the jet noise source back toward the nozzle lip and thus provide a longer propagation length for an acoustic lining to reduce the internal mixing noise. Mixing enhancement of the supersonic jet flow from a converging-diverging rectangular nozzle operated at design pressure was obtained using paddles to induce screech and cause jet flapping.

Seiner and $\mathrm{Krejsa}^{1}$ have discussed the status of supersonic jet noise reduction relative to the supersonic transport. A large reduction in jet noise will be necessary for such an aircraft to meet anticipated noise goals. The work reported in this paper is intended to explore the two approaches mentioned above to help provide an efficient method to achieve some of this required noise reduction. 


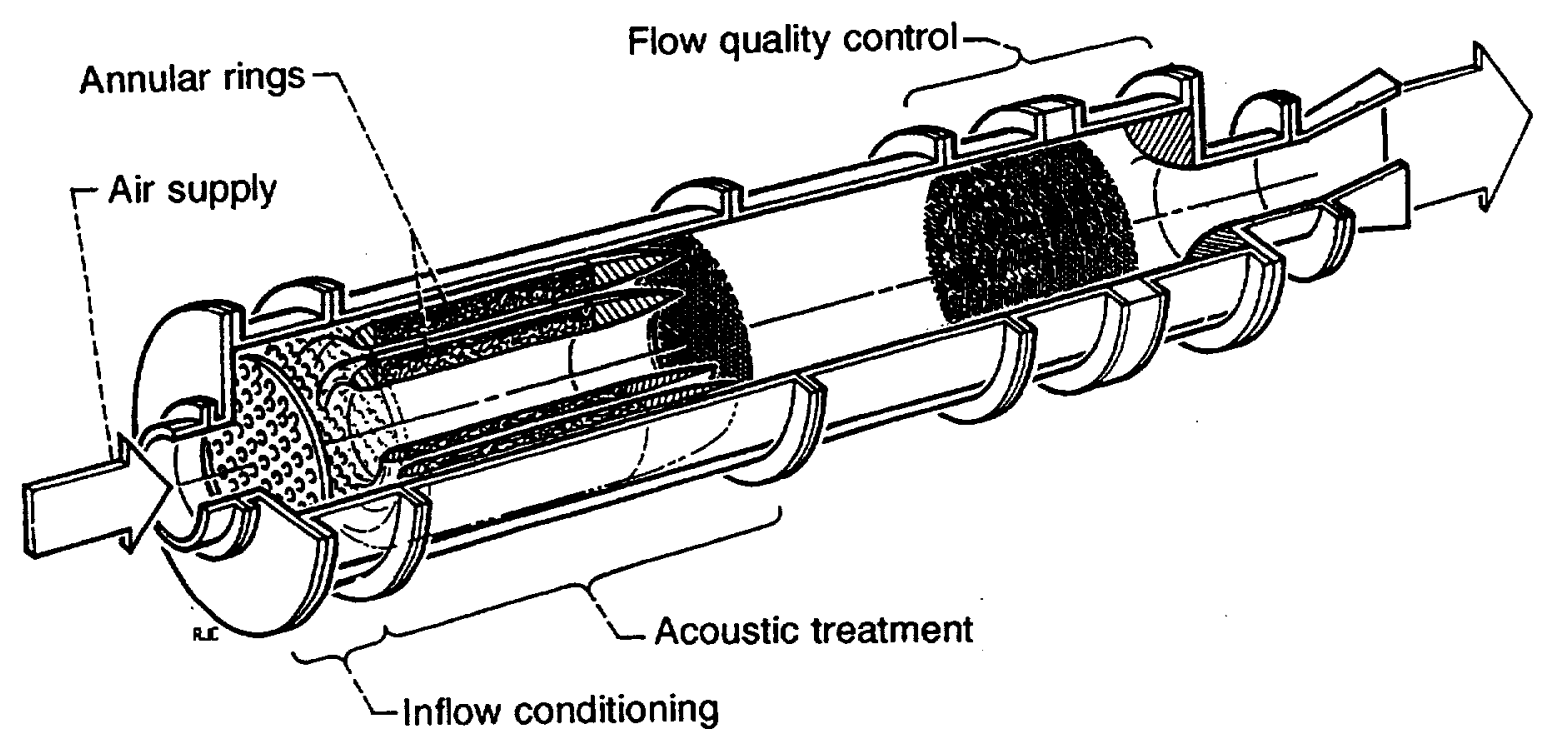

Figure 1. Schematic of supersonic jet flow rig

$\mathrm{Tam}^{2}$ and Lilley ${ }^{3}$ have provided excellent recent reviews of the fundamentals of jet noise production. The idea that the jet noise is intimately involved with the large coherent structures produced in the jet mixing process is particularly relevant here. This paper reports research based upon the manipulation of these structures to try to effect a jet noise reduction.

Seiner $^{4}$ et al. and Ponton ${ }^{5}$ et al. have extensively measured the noise produced by supersonic rectangular jets. Wlezien and Kibens ${ }^{6}$ have conducted experiments on the noise generated by supersonic jets formed by round nozzles with unsymmetrical exits. One additional element found in the research reported here is that some of the nozzles are converging-diverging nozzles running nearly shock free at the design pressure differing from the previously reported converging nozzles with the resulting strong shock structures. A second additional element is that the jet instability and thus the large coherent structures are manipulated to alter the jet noise. Also the double bevelled converging-diverging nozzle discussed here has the flow emerging almost axially rather than being diverted to the side as in the converging nozzles of reference 6 .

This paper represents an extension of the work reported by Rice and $\operatorname{Raman}^{7,8}$. In reference 7 the use of paddles was first introduced to induce a resonant screech tone to provide greatly increased jet mixing. In reference 8 the supersonic flow fields for the bevelled rectangular nozzles were presented. In both references 7 and 8 the concentration was on the aerodynamics of the process while in this paper the acoustic effects are emphasized.

\section{$\underline{\text { Experiment }}$}

\section{Air Flow Facility}

A schematic drawing of the flow facility used in this experiment is shown in Fig. 1. The high pressure air enters at the left into the $76 \mathrm{~cm}$ diameter plenum where it is laterally distributed by a perforated plate and a screen. Two circumferential acoustically treated splitter rings

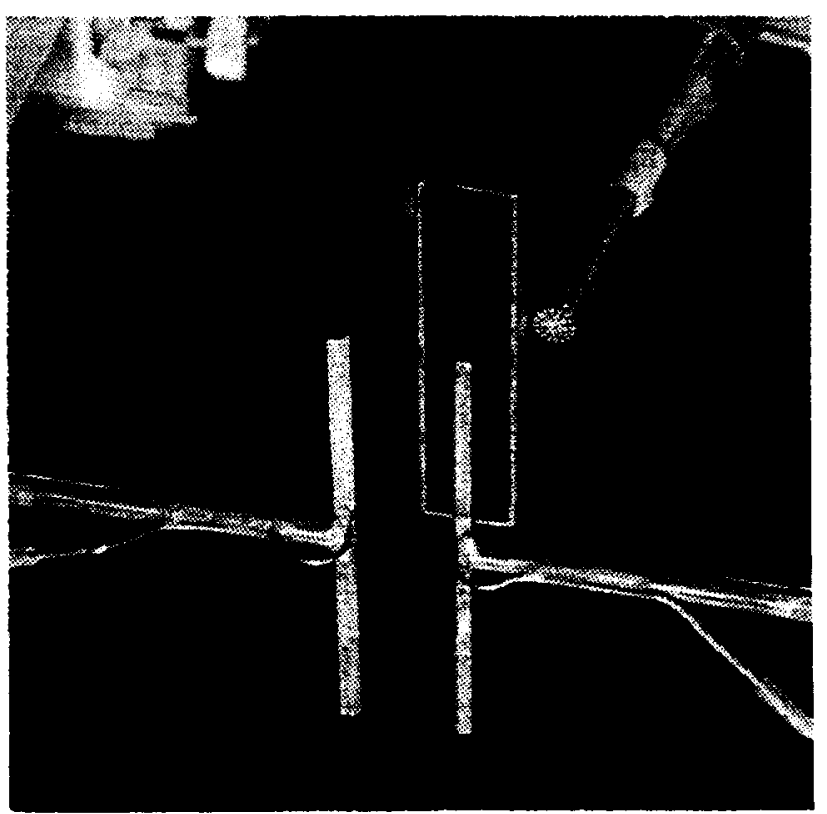

Figure 2. Rectangular nozzle and paddles 
remove the upstream valve and entrance noise. The flow is further conditioned by two screens before undergoing two area contractions of $\mathbf{3 . 5}$ and $\mathbf{1 3 5}$ for the rectangular nozzles used in this experiment. The nozzle shown in Fig. 1 is not drawn to scale but is greatly enlarged.

\section{Nozzles and Paddles}

A close-up view of the nozzle is shown in Fig. 2. A $6.4 \mathrm{~mm}$ microphone is seen taped to the nozzle just behind the nozzle lip. A set of full length paddles (76 $\mathrm{mm})$ are mounted in their support structure. This structure has three-dimensional movement and paddle spacing adjustment which are remotely controlled from the control room. On the paddle support shafts the tubing for the total pressure taps can be seen. These pressure taps face toward the nozzle and are flush with the flow side of the paddle. There are also strain gages mounted on the paddle support posts. These measure the axial force on the paddles.

The five nozzle geometries tested in this program are shown in Table 1. The dimensions shown are the nozzle exit long dimension (L), exit small dimension $\left(\mathrm{H}_{\text {exi }}\right)$, and the throat dimension $\left(\mathrm{H}_{\text {thr }}\right)$. Note there are three main nozzle types: single-bevelled (3C), straight (4C, 6CD), and double-bevelled (9C, 9CD). All bevel cuts were made at thirty (30) degrees from the exit lip. The straight and the double-bevelled types have both a converging version which was operated under-expanded and a converging-diverging version which was run at design pressure ratio. All of the nozzles were made from $50 \mathrm{~mm}$ copper pipe. Internal forms were forced into the pipe as the exterior was hammered until the form proceeded to the proper axial location. A separate internal form with a 2.5 degree half angle was used to shape the diverging portion of the C-D nozzles. Nozzles $4 C$ and $6 C D$ had final mill cuts applied to the internal surface at the exit to provide more accurate dimensions. The throat and exit dimensions were accurate and uniform to about $0.1 \mathrm{~mm}$. It should be noticed from the above description of the nozzles that these are not precision polished specimens. It was felt that this level of sophistication was sufficient for the first cut screening reported here and that any phenomenon requiring extreme accuracy and polished surfaces could not be maintained in practice in an actual engine.

\section{Acoustic Instrumentation and Procedure}

During acoustic data acquisition the nozzle was mounted as shown in Fig. 2 in the vertical position (along with the paddles if they were used). The microphone shown strapped to the nozzle was removed. A $6.4 \mathrm{~mm}$ microphone with windscreen was mounted facing upstream in a three dimensional traversing mechanism. The microphone traverse was computer controlled providing $7.62 \mathrm{~cm}$ increments during an axial traverse. The microphone was manually moved in the transverse direction to start a new axial traverse. In the vertical plane (Z-X plane through the large dimension of the nozzle) axial traverses from $X=-22.9 \mathrm{~cm}$ to $+1.22 \mathrm{~m}$ were performed at $\mathrm{Z}=7.62,10.2,12.7,15.2,22.9$, $30.5,38.1,45.7$, and $53.3 \mathrm{~cm}$. The vertical plane traverses were conducted above the nozzle away from the floor. In the horizontal plane (Y-X plane through the small dimension of the nozzle) axial traverses from $X=$ $7.62 \mathrm{~cm}$ to $+1.22 \mathrm{~m}$ were performed at $-\mathrm{Y}=7.62,10.2$, $12.7,15.2,17.8,20.3,25.4$, and $30.5 \mathrm{~cm}$. The axial reference was the nozzle exit. A single microphone was used thus eliminating the problem of differences in multichannel systems. The microphone was calibrated using a standard piston-phone. The aerodynamic instrumentation used in these experiments has been thoroughly discussed in reference 7.

The acoustic signal was analyzed using a digital two channel instrument. The narrow band spectrum was

TABLE 1. NOZZLE CONFIGURATIONS TESTED

\begin{tabular}{||l|l|l|l|l|l||}
\hline \hline NOZZLE & CONFIGURATION & $\mathrm{L}, \mathrm{mm}$ & $\mathrm{H}_{\text {exi }}, \mathrm{mm}$ & $\mathrm{H}_{\mathrm{trr},}, \mathrm{mm}$ & $\begin{array}{l}\text { ASPECT } \\
\text { RATIO }\end{array}$ \\
\hline 3C & Single-Bevel, Converg. & 66.0 & 13.5 & 13.5 & 4.893 \\
\hline 4C & Straight Exit, Converg. & 65.8 & 13.2 & 13.2 & 4.969 \\
\hline 6CD & Straight Exit, C-D & 68.1 & 14.1 & 12.5 & 4.817 \\
\hline 9C & Double-Bevel, Converg. & 64.8 & 13.7 & 13.7 & 4.728 \\
\hline 9CD & Double-Bevel, C-D & 69.3 & 13.3 & 11.7 & 5.200 \\
\hline
\end{tabular}


converted to $1 / 3$ octave data using a computer. All noise data reported here are thus $1 / 3$ octave data except when tones may be discussed.

\section{Acoustic Results}

The results of the two experiments will now be presented. The first set of results show the noise of the bevelled rectangular nozzles compared to the conventional rectangular nozzles. Each comparison will be made for the same types of nozzles (either converging or converging-diverging). The comparisons are made between nozzles $9 C D$ and $6 C D, 9 C$ and $4 C$, and $3 C$ and 4C (see Table 1). The acoustic data at the extreme limits of our traversing mechanism might be considered to still be near-field ( 25 to 100 times the nozzle small dimension), but it should be sufficiently close to far-field to be used at least for comparative purposes.

The second phenomenon of induced screech using the conventional converging-diverging rectangular nozzle (6CD) will then be presented. The results will show the effect on the jet mixing and the jet mixing noise source location. The acoustic data will be very near-field since this induced screech mixing method would most likely be used within the shroud of a mixer-ejector system and only in such a system would there be an acoustic advantage using this mixing enhancement method.

\section{Acoustic Benefit of Bevelled Nozzles}

The evaluation of the acoustic benefit of bevelled nozzles is quite a complex process since the benefit is situation or hardware dependent. For example, it will be shown below that a bevelled rectangular nozzle with supersonic flow operated out in the open is noisier than its baseline counterpart because it produces about an additional ten decibels of very high frequency broadband

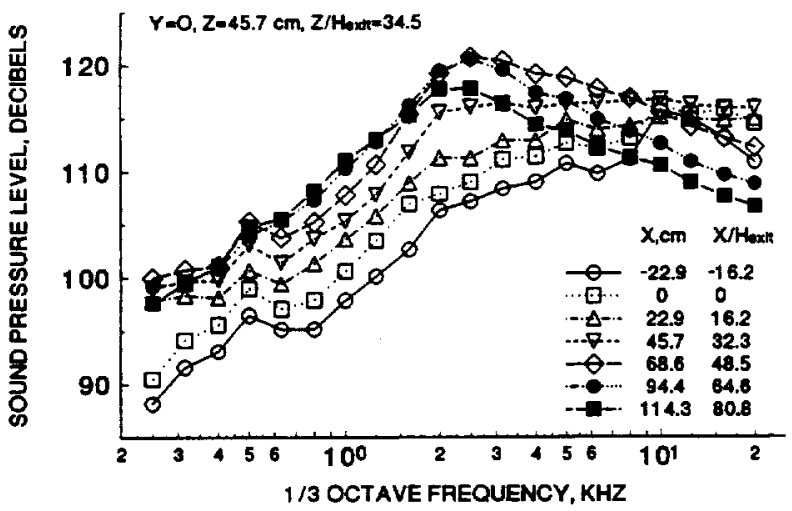

Figure 3. Noise spectra for nozzle $6 C D$, Mexp $=1.395$, sideline plane of large nozzle dimension, $45.7 \mathrm{~cm}$ from axis noise near the plane of the nozzle exit. However if this nozzle is enclosed in a properly designed acoustically treated shroud as in a mixer ejector, this excess noise does not present a problem. We will attempt to show here that the bevelled nozzle provides a noise directivity and spectrum shift that can be beneficial if the system is properly designed. The noise directivity shift is precisely the property mentioned in the Introduction section which has been sought to render the mixing noise more amenable to attenuation by acoustic liners. A complete analysis of the acoustic benefits of the bevelled nozzle is beyond the scope of this paper, but some of the acoustic elements which must be considered in such an analysis will be discussed.

The measured noise spectra for the baseline C-D nozzle 6CD are shown in Fig. 3. All of the data are for a constant distance sideline of $45.7 \mathrm{~cm}$ from the nozzle axis in the plane of the large nozzle dimension. Seven equally spaced axial positions are shown from behind the nozzle plane $(-22.9 \mathrm{~cm})$ to quite far downstream from the nozzle $(114.3 \mathrm{~cm})$. For later more detailed analysis, twenty positions spaced at $7.6 \mathrm{~cm}$ are available but they would unnecessarily clutter the graph. As would be expected, near the nozzle exit plane the noise spectra is dominated by very high frequency noise. As the microphone is moved downstream, the mixing noise centered at $2.5 \mathrm{kHz}$ becomes dominant and is seen to peak somewhere between 68 and $94 \mathrm{~cm}$ (actually $84 \mathrm{~cm}$ ) at a level of $121.1 \mathrm{~dB}$.

The noise spectra for the double bevelled C-D nozzle $9 \mathrm{CD}$ measured at the same sideline positions are shown in Fig. 4. The very noticeable difference in these spectra from those of Fig. 3 is the nearly ten decibel increase in the very high frequency noise mainly near the plane of the nozzle. It is tempting to attribute this high frequency noise increase to shock associated broadband noise as presented by Tam and $\operatorname{Tanna}^{9}$ and $\operatorname{Tam}^{10}$ et al. since the

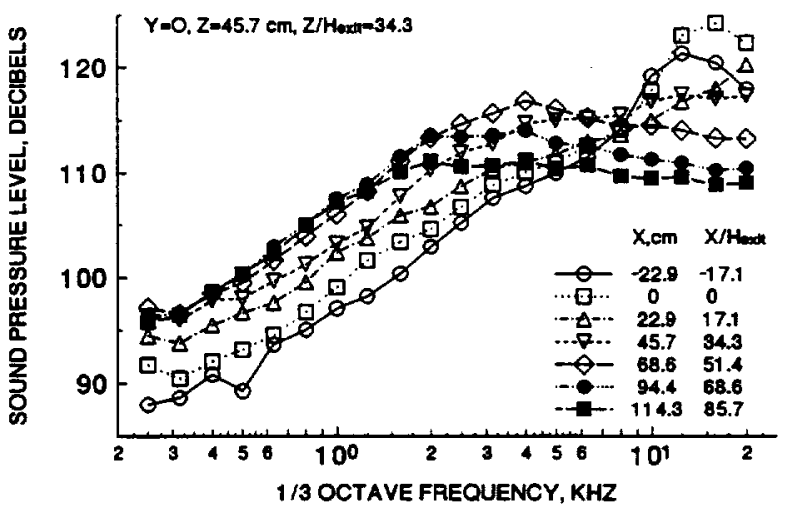

Figure 4. Noise spectra for nozzle $9 C D$, Mexp $=1.425$, sideline plane of large nozzle dimension, $45.7 \mathrm{~cm}$ from axis 


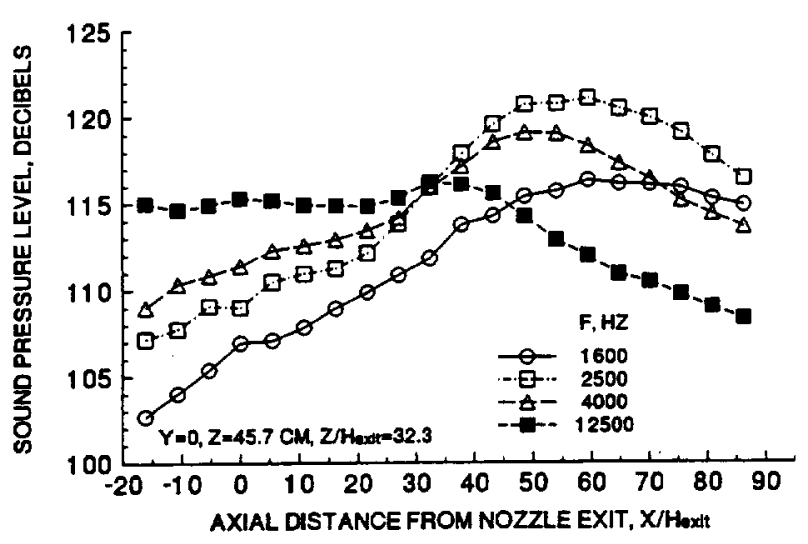

Figure 5. Axial distribution of sound pressure level, sideline $Z=45.7 \mathrm{~cm}$

Nozzle 6CD, Moxp $=1.395$

frequency relationship to mixing noise is about correct. However, this jet is properly expanded and does not have sufficiently strong shocks to sustain a significant screech tone even near the nozzle lip (about $138 \mathrm{~dB}$ ). It is possible that the oblique bevel of this nozzle exit has promoted the dominance of oblique instability modes which was the reasoning behind trying such a nozzle. The source of this high frequency noise is unknown at present. As mentioned earlier, this high level noise dominates the spectrum only near the plane of the nozzle where it would experience nearly normal incidence onto an acoustic liner in a properly designed shrouded mixerejector. It is thus of no consequence for the purposes of this study but could pose a problem for other configurations.

Other characteristics of the nozzle $9 C D$ noise spectra can be seen in Fig. 4. The mixing noise peak has shifted to a higher frequency of $4 \mathrm{kHz}$. The peak occurs at $\mathrm{X}=$ $68.6 \mathrm{~cm}$ at a level of $116.9 \mathrm{~dB}$. The reduction in the peak mixing noise level from 121.1 to $116.9 \mathrm{~dB}$ represents an obvious advantage for the bevelled nozzle. However, the shift in the location of this peak from $84 \mathrm{~cm}$

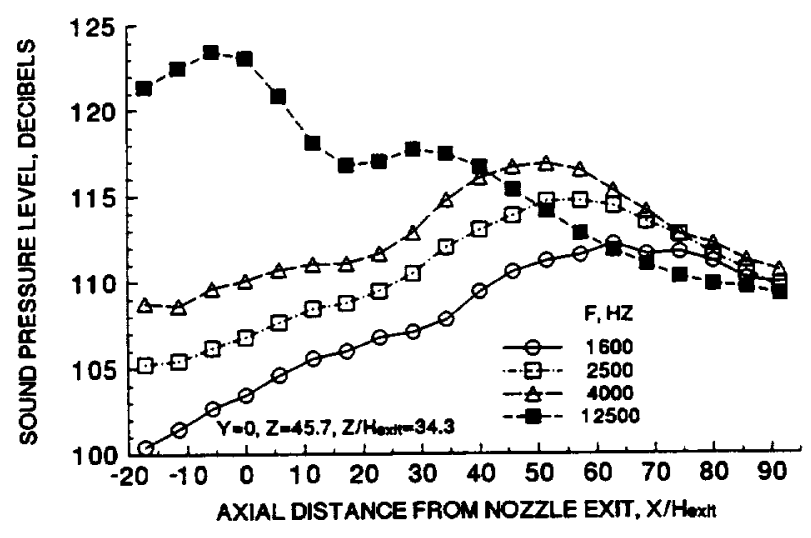

Figure 6. Axial distribution of sound pressure level, sideline $Z=45.7 \mathrm{~cm}$ Nozzle 9CD, Moxp=1.425 to $69 \mathrm{~cm}$ represents another advantage for the bevelled nozzle which is not quite so obvious. The upstream location of the peak means that the noise must propagate a longer distance to reach the end of a given mixer-ejector system and in addition could be propagating at a larger angle to the jet axis. If used in conjunction with a properly designed and located acoustic liner in a shrouded configuration, the more normal angle of incidence of the noise on an acoustic liner will provide improved acoustic suppression for a given liner length.

Cross plots of the data in Figs. 3 and 4 are shown in Figs. 5 and 6 . The latter plots show the directivity information more clearly and are simplified by using only representative frequencies. The peak frequencies of the mixing noise, $2500 \mathrm{~Hz}$ and $4000 \mathrm{~Hz}$, for the two nozzles are retained. The one-third octave band at $12,500 \mathrm{~Hz}$ is used as representative of the high frequencies without contamination from screech tones or harmonics where they occur. The $1600 \mathrm{~Hz}$ band represents broadband noise below the mixing noise peaks for any of the nozzles studied here. The bands at $5,000 \mathrm{~Hz}$ and $10,000 \mathrm{~Hz}$ were avoided to eliminate the screech tone and harmonic when they occurred (underexpanded converging nozzles). Bevelling the nozzles when screech occurs produces very large screech level reductions but this was not the emphasis of this study.

The same noise characteristics discussed relative to Figs. 3 and 4 can be seen more clearly in Figs. 5 and 6. In addition the difference between the noise level curves in Figs. 5 and 6 are plotted in Fig. 7 which provides a good condensation of the acoustic differences between nozzles $9 \mathrm{CD}$ and $6 \mathrm{CD}$. The large increase in high frequency noise is evident near the plane of the nozzle and the jet mixing noise reduction is evident in the down stream direction. This sound pressure level difference format will be used to present the results for the remainder of the nozzle configurations. The frequencies

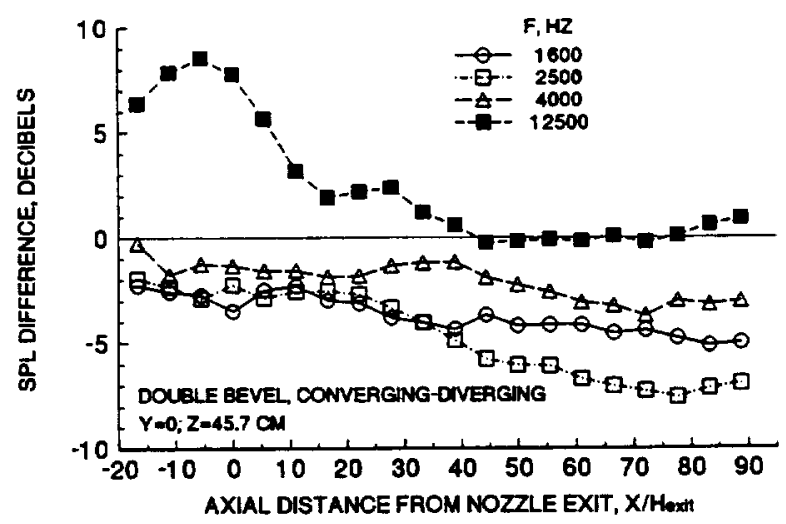

Figure 7. Sound pressure level difference, sideline $Z=45.7 \mathrm{~cm}$ SPLnOZ.oCD - SPLnOZ.6CD, design pressures 
at the peaks of the mixing noise remained at $2500 \mathrm{~Hz}$ and $4000 \mathrm{~Hz}$ for the straight and bevelled nozzles for all of the configurations.

The acoustic influence of using a double bevelled exit with a converging rectangular nozzle operating underexpanded is summarized in Figure 8. The large increase in the sound pressure level ,SPL, at high frequencies near and ahead of the plane of the nozzle exit is again evident. The very large reduction, nearly $12 \mathrm{~dB}$, in mixing noise at $2500 \mathrm{~Hz}$ in the far downstream direction is evident. However, now a $5 \mathrm{~dB}$ increase in mixing noise at $4000 \mathrm{~Hz}$ is seen. This is mainly due to a large upstream directivity shift and high frequency shift of the mixing noise for the double bevelled nozzle. An acoustic liner would have to absorb this $5 \mathrm{~dB}$ hump to make this geometry effective. This may be quite possible due to the upstream directivity shift of the noise.

The final bevelled nozzle geometry is the single bevelled converging nozzle, $3 \mathrm{C}$. The acoustic data for this nozzle are compared to the standard straight exit converging nozzle, 4C, in Fig. 9. The data were taken on the bevelled side (higher SPL side) of this unsymmetrical nozzle. Again the high frequency SPL increase is evident near the plane of the nozzle and substantial mixing noise reductions are evident in the downstream direction.

It is evident from the acoustic data presented above that all jets from the bevelled rectangular nozzles have some common properties. All had large increases in high frequency noise near the plane of the nozzle. This should not be a big problem when an acoustically lined duct can be used around the jets because of the upstream position and normal to the wall directivity of the source. All geometries had reductions in the level of the mixing noise at far downstream positions and a shift to higher frequency at the peak. A more detailed study must be made to determine how to best take advantage of these

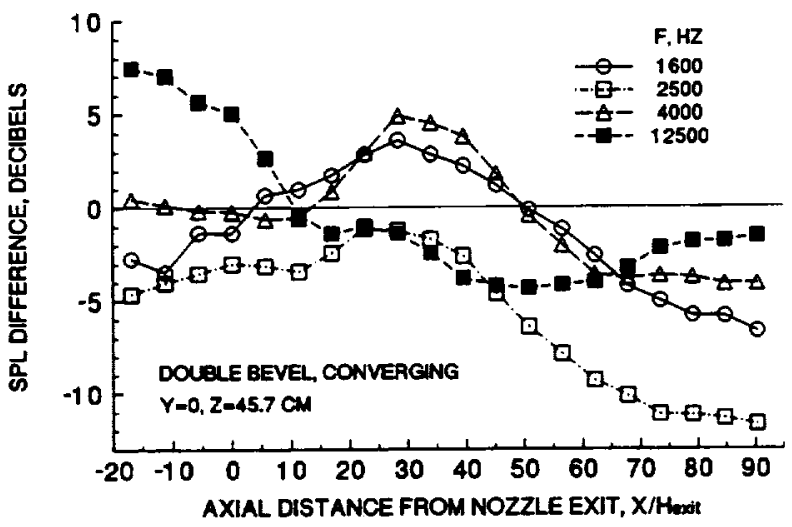

Figure 8. Sound pressure level difference, sideline $Z=45.7 \mathrm{~cm}$ SPLNOZ.x - SPLNOZ.4C, design pressures properties when a bevelled nozzle might be used with acoustic treatment on the walls of a mixer-ejector system.

\section{Aerodynamic Properties of Bevelled Nozzles}

The supersonic jet flow field from bevelled rectangular nozzles was the subject of the study reported in reference 8. All of this information is not repeated here, but some flow properties can be summarized which are useful in the current discussion. Jets from bevelled converging rectangular nozzles are deflected from the axial direction due to the transverse pressure gradient present at the bevelled exit. This property was also evident in the round jets reported by Wlezien and Kibens ${ }^{6}$. The single bevelled nozzle flow diverts unsymmetrically from the axis. The double bevelled nozzle flow spreads symmetrically about the jet axis and was observed to produce increased mixing over the other geometries as measured by mass entrainment. This nozzle might be an excellent choice for some applications which are consistent with these flow properties. The double bevelled converging-diverging rectangular nozzle produces a jet with very little divergence over that of the straight exit CD nozzle. This is probably due to the inability of the transverse pressure gradient to exert an influence across the supersonic flow in the diverging nozzle exit.

\section{Acoustic Propagation Angle}

The upstream shift in the axial position of the peak in the mixing noise of the jets from the bevelled nozzles is beneficial if acoustic linings are to be used in the duct of a mixer-ejector system. It is of interest to determine if the upstream shift was caused by an upstream shift in the source location or by an increase in the radiation angle toward the sideline. To study this effect in an approximate manner the acoustic data was analyzed in the

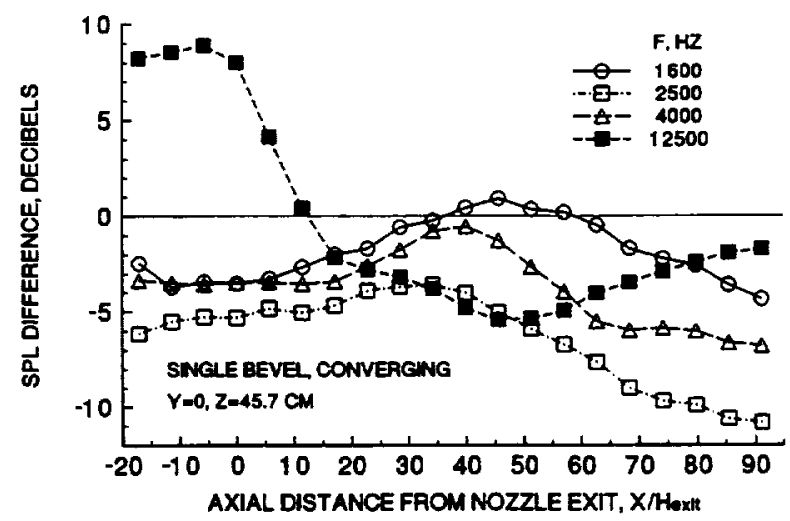

Figure 9. Sound pressure level difference, sideline $Z=45.7 \mathrm{~cm}$ SPLNOZ.3C - SPLnOZ.4G, Moxp $=1.40$ 


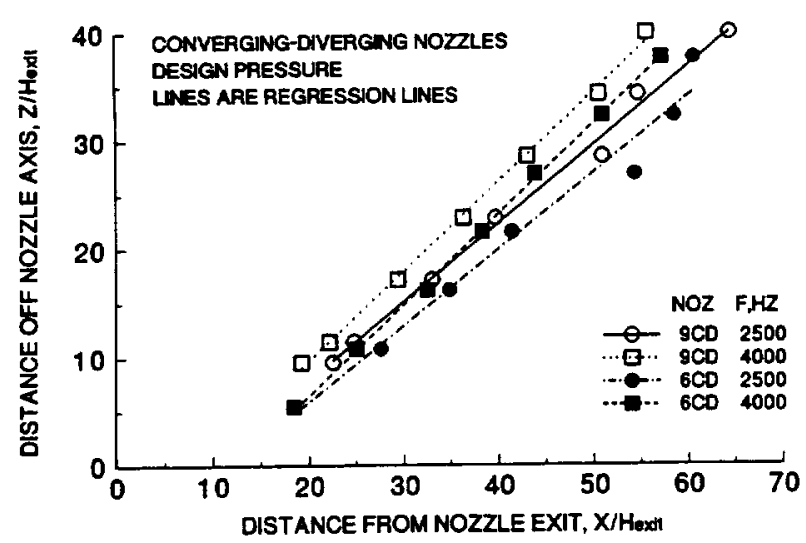

Figure 10 . Loci of maximum radiation, nozzles $9 C D$ and $6 C D$

following way. In the plane of the large nozzle coordinate, at each constant sideline distance $(Z)$ the axial location $(X)$ of the maximum sound pressure level was located for each frequency. These coordinates are related to but not equal to the peak contours in the acoustic radiation pattern. Since the radiation of interest here, mixing noise, propagates at an angle to the downstream axis, the maximum coordinates derived above would be slightly upstream and outboard from the actual peak. However, the maximum radiation coordinates are sufficient for comparative purposes and are plotted in Fig. 10 for the two converging-diverging nozzles $6 \mathrm{CD}$ (straight) and 9CD (double-bevelled). The loci for two frequencies, 2500 and $4000 \mathrm{~Hz}$, are shown which are the peaks in the mixing noise spectra at the $Z=45.7 \mathrm{~cm}$ sideline for the two nozzles. The lines through the data are the linear regression curve-fits. Note that the regression lines for a given frequency are parallel to each other for both frequency cases. The curves for nozzle $9 \mathrm{CD}$ are just shifted upstream from those of nozzle $6 \mathrm{CD}$ which indicates a source position shift with no radiation angle shift. The lines for $4000 \mathrm{~Hz}$ are at a greater angle

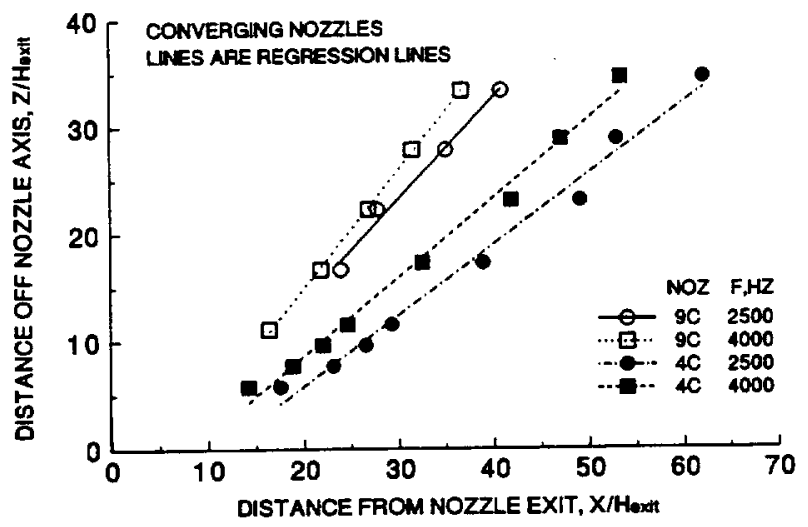

Figure 11. Loci of maximum radiation, nozzles $9 \mathrm{C}$ and $4 \mathrm{C}$, Moxp $=1.40$ to the axis than the $2500 \mathrm{~Hz}$ lines which would be expected for the slightly higher frequency.

The maximum radiation data for the converging nozzles 4C (straight) and 9C (double-bevelled) are shown in Fig. 11. This case, converging nozzles, is substantially different from that of the previous converging-diverging nozzles. The double-bevelled nozzle, $9 C$, is seen to cause a shift in the source position upstream and also to increase the noise propagation angle toward the upstream direction. This is a double benefit when using acoustic liners, but this advantage may be somewhat diminished since the mixing noise peak also increased in magnitude (see Fig. 8). A complete analysis of the mixer-liner system must be made to determine the overall advantage.

The increase in radiation angle for nozzle $9 \mathrm{C}$ may be due to the transverse spreading of the jet responding to the transverse pressure gradient generated at the bevelled exit. As discussed in reference 8 and summarized in the previous section, the converging-diverging double bevelled nozzle $(9 \mathrm{CD})$ does not experience this spreading and does not have a radiation angle shift.

\section{Acoustic Benefit of a C-D Nozzle}

The acoustic advantage of using a straight convergingdiverging nozzle over a straight converging nozzle, both rectangular, is seen in Fig. 12. The sideline noise difference at $\mathrm{Z}=45.7 \mathrm{~cm}$ is plotted for several representative frequencies. The open symbols, 1600 to $4000 \mathrm{~Hz}$, represents the jet mixing noise with the peak at $2500 \mathrm{~Hz}$. The screech tone for the converging nozzle $(4 \mathrm{C})$ is in the $5000 \mathrm{~Hz}$ band with harmonics in the higher frequency bands all shown as filled symbols. Both nozzles are operated at the fully expanded Mach number, $M_{\text {exp }}=1.4$. Nozzle 6CD is at design pressure and nozzle $4 C$ operates underexpanded. The peak mixing noise is seen to be reduced by about $3.5 \mathrm{~dB}$. The screech tone is

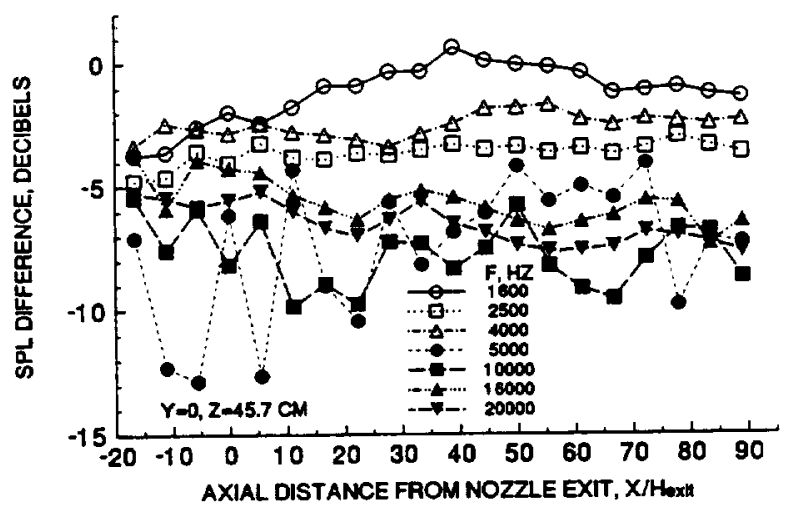

Figure 12. Acoustic benefit of converging-diverging nozzle over converging nozzle, SPLNOZ.600 - SPLNOZ4C, Moxp=1.4 


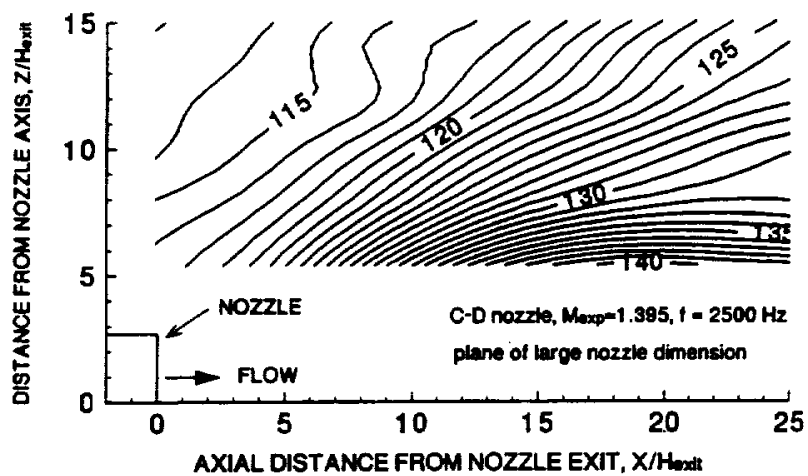

Figure 13. Near-field noise measurements, nozzle $6 \mathrm{CD}$, no paddles

seen to be reduced by nearly $13 \mathrm{~dB}$ near the nozzle plane and the higher frequency harmonics likewise experience significant reductions.

\section{Induced Screech and Near-Field Jet Noise}

In this section the effect on jet mixing noise from high levels of induced screech excitation will be shown. The paddles as shown in Fig. 2 are inserted into the shear layers on the long sides of the nozzle. The paddles take the place of shocks in the feedback loop and it is because of this analogy that the "induced screech" terminology is used here. The induced screech level at the nozzle lip increases from 142 to $157.8 \mathrm{~dB}$ using the longest paddles for the insertion used in this experiment. The jet experiences a violent flapping mode when excited by the induced screech. This is clear from the Schlieren photographs reported in reference 7. Large nonlinear (not sinusoidal) wave amplitudes were seen to be excited which caused the jet to alternately impinge upon the paddles producing large oscillating pressures on the paddles. The paddles appeared to be acting as a simple source as suggested by Powell ${ }^{11}$ for higher speed flows. The forces on the two paddles were out of phase which

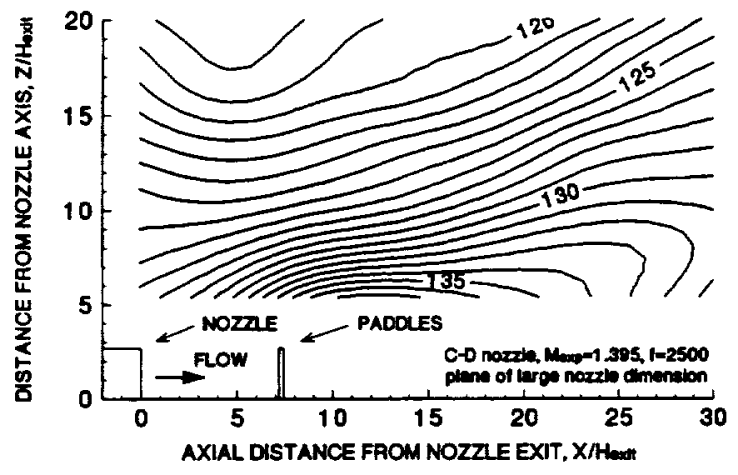

Figure 14. Near-field noise measurements, nozzle $6 \mathrm{CD}$, long paddles was required to sustain the flapping instability of the jet. As the oscillating flow passed the paddles large oscillating vorticity was imparted on the flow which sustained the increased mixing downstream from the paddles. A complete discussion of the mixing enhancement of the jet can be found in reference 7 .

The $1 / 3$ octave noise near-field produced by the conventional convergent-divergent rectangular nozzle (6CD) operated at design pressure without paddles is shown in Fig. 13. The nozzle profile is shown to scale at the lower left side of the figure. Some interesting features of the noise field should be pointed out. Very near to the jet flow, where the constant noise contours are almost parallel to the jet, the oscillating pressure is caused by the potential field of the passing large coherent structures. In Fig. 13, the coherent structures passing at $2500 \mathrm{~Hz}$ are seen to peak at an axial location of about twenty times the nozzle small dimension $\left(X / H_{\text {exit }}=20\right)$. This peak location is an average value since the unsteady pressure is averaged over one hundred samples by the digital spectral analyzer. Further from the nozzle axis the coherent structure potential field falls off rapidly, as seen by the tight contour spacing near the jet, and the radiated acoustic field becomes more dominant. For a fairly highly directional noise source, a lobed pattern of the contours becomes apparent. This lobed pattern will become more obvious in the next figure as the radiation lobe is brought into the field of view.

In Fig. 14 the noise near-field is shown for nozzle $6 \mathrm{CD}$ when the full length paddles $(76.2 \mathrm{~mm})$ are installed to induce screech and increase jet mixing. Again the nozzle and paddles are shown to scale at the lower left of the figure. The coherent structures are seen to peak out at $\mathrm{X} / \mathrm{H}_{\text {exit }}=12$ to 13 , a significant reduction from the value of 20 for the unexcited jet. The lobed pattern of the noise radiation is now seen at the lower right of the figure. The paddles have thus moved the jet mixing and the jet noise radiation source nearer to the nozzle exit. The mixing enhancement has been inferred here from the noise near-field but this really just agrees with the aerodynamic data for this configuration documented in reference 7.

The noise difference for nozzle $6 \mathrm{CD}$ with and without the paddles is shown in Fig. 15 for the $Z=45.7 \mathrm{~cm}$ sideline in the plane of the large nozzle dimension. The open symbols represent the jet mixing noise and the filled symbols the induced screech and harmonics. For this analysis the screech is included since it is produced by the paddles and must be weighed in any noise comparison. For this data, at least approximating the far-field, the noise increase due to the paddles does not look promising. The jet mixing noise has increased by about $3 \mathrm{~dB}$ and the 


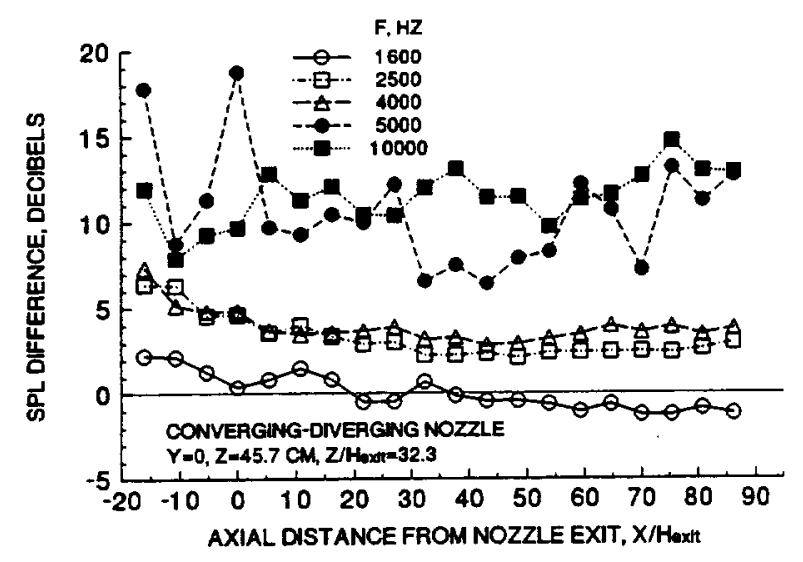

Figure 15. Sound pressure level difference, sideline $Z=45.7 \mathrm{~cm}$ Nozzle 6CD, SPLiong paddles - SPLno paddles, Mexp=1.40

induced screech and its harmonic has about a $10 \mathrm{~dB}$ increase even at the downstream locations. The contour plots of Figs. 13 and 14 showed the mixing enhancement benefit using the paddles, but this benefit is lost in the farfield. Recall that the stated application of interest here is an acoustically lined mixer-ejector system and the very near-field behavior is most important. The noise difference in the very near field due to using paddles and induced screech with nozzle 6CD is shown in Fig. 16. Notice that the large increases in sound pressure level occur ahead of the paddles which are located at $X / H_{\text {exit }}=7.2$. At the higher axial distances all of the SPL levels are falling off. This very near field has a very complex structure with any measurement being a mixture of propagating sound and coherent structure potential field moving at convective velocity. The SPL levels at least ahead of the nozzle exit are probably dominated by acoustic propagation while the downstream values may be

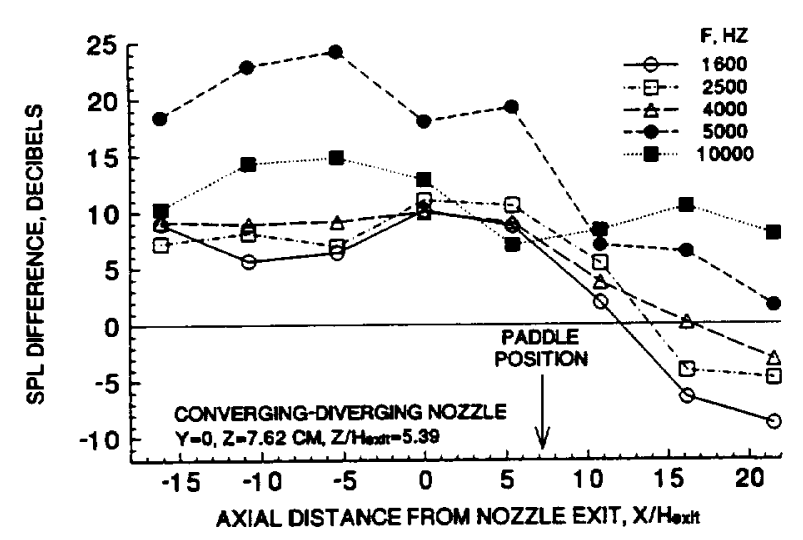

Figure 16. Sound pressure level difference, very near-field, $Z=7.62 \mathrm{~cm}$ Nozzle 6CD, SPLiong peddies - SPLno peddea, Maxp $=1.40$ potential field dominated. From Figs. 13, 14, and 16 it appears that the enhanced mixing due to the induced screech of the paddles has moved the action upstream and it just might be possible to exploit this situation using properly designed acoustic treatment.

\section{Concluding Remarks}

Two very different jet noise reduction concepts have been presented in this paper. The first concept uses a bevelled exit for a rectangular nozzle producing a supersonic jet. Converging-diverging and diverging nozzles were tested. Both single (unsymmetrical) and double bevelled (symmetrical) cases were used. The double bevelled $C D$ nozzle showed clear advantages over that of a straight exit $C D$ nozzle. A $4.2 \mathrm{~dB}$ reduction in jet mixing noise level was observed. All of the bevelled nozzles tested showed a jet mixing noise spectral shift to higher frequency and an upstream location shift. The location shift could be due to upstream source noise location and/or radiation angle increase both being advantageous when wall acoustic treatment is used. All bevelled geometries produced a large increase in high frequency noise but it was mainly near the plane of the nozzle and could thus be easily absorbed by wall treatment.

The second concept, the use of screech inducing paddles with the supersonic rectangular jet of a convergingdiverging nozzle operated at design pressure may be useful for internal use in an acoustically treated mixerejector nozzle system. The jet mixing was shown to increase dramatically moving the jet noise source location back toward the mixer nozzle lip. This provides a longer acoustic path length for the internal mixing noise as it passes through the acoustically treated duct section. Farfield noise analysis showed a substantial increase in jet mixing noise and of course in induced screech level. Very near-field analysis showed that the noise source increases were confined near the nozzle exit and the screech inducing paddle location. It is possible that properly designed acoustic treatment might take advantage of this upstream source shift.

Additional study should be conducted on both of these concepts. Only a single bevel angle, 30 degrees, has been tried. The study has been limited to a fully expanded Mach number of 1.4. For the screech inducing paddles, drag losses must be minimized while retaining mixing enhancement and a more upstream directed screech noise field would be beneficial. For all of the above, the influence of confining walls and acoustic treatment must be studied. 


\section{$\underline{\text { References }}$}

1. Seiner, J.M., and Krejsa, E.A., "Supersonic Jet Noise and the High Speed Civil Transport, " AIAA Paper No. 89-2358, July 1989.

2. Tam, C.K.W., "Jet Noise Generated by Large-Scale Coherent Motion, " Aeroacoustics of Flight Vehicles: Theory and Practice, Vol. 1: Noise Sources, NASA RP 1258, WRDC TR 90-3052, Aug. 1991, pp. 311390.

3. Lilley, G.M., "Jet Noise Classical Theory and Experiments," Aeroacoustics of Flight Vehicles: Theory and Practice, Vol. 1: Noise Sources, NASA RP 1258, WRDC TR 90-3052, Aug. 1991, pp. 211289.

4. Seiner, J.M., Ponton, M.K., and Manning, J.C., "Acoustic Properties Associated with Rectangular Geometry Supersonic Nozzles," AIAA Paper No. 86-1867, July 1986.

5. Ponton, M.K., Manning, J.C., and Seiner, J.M., "Far-Field Acoustics of Supersonic Rectangular Nozzles with Various Throat Aspect Ratios, " NASA TM 89002, 1986.

6. Wlezien, R.W., and Kibens, V., "The Influence of Nozzle Asymmetry on Supersonic Jets," MDRL 862, also presented at the AIAA 24th Aerospace Sciences Meeting, Reno, Nevada, 6-8 January 1986.

7. Rice, E.J., and Raman, G., "Enhanced Mixing of a Rectangular Supersonic Jet by Natural and Induced Screech," AIAA Paper No. 93-3263, July 1993.

8. Rice, E.J., and Raman, G., "Supersonic Jets From Bevelled Rectangular Nozzles," accepted for presentation at the Winter Annual Meeting of the ASME, Symposium on Flow Acoustics Interaction and Fluid Control, November 28-December 3, 1993, New Orleans, La.

9. Tam, C.K.W., and Tanna, H.K., "Shock Associated Noise of Supersonic Jets from Convergent-Divergent Nozzles," Journal of Sound and Vibration, Vol. 81, No. 3, pp. 337-358, 1982.

10. Tam, C.K.W., Seiner, J.M., and Yu, J.C., "Proposed Relationship Between Broadband Shock Associated Noise and Screech Tones," Journal of
Sound and Vibration, Vol. 110, No. 2, pp. 309-321, 1986.

11. Powell, A., "On the Edgetone," The Journal of the Acoustical Society of America, Vol. 33, No. 4, April 1961, pp. 395-409. 
Public reporting burden for this collection of information is estimated to average 1 hour per response, including the tine for reviewing instructions, searching existing data sources, gathering and maintaining the data needed, and completing and reviewing the collection of information. Send comments regarding this burdon estimate or any other aspect of this collection of information, including suggestions for reducing this burden, to Washington Headquarters Services, Directorate for Intormation Operations and Reports, 1215 Jeflers
Davis Highway. Suite 1204, Arlingtion, VA 22202-4302, and to the Office of Management and Budget. Papenwork Reduction Project (0704-0188), Washington, DC 20503.

\begin{tabular}{|l|c|c|}
\hline 1. AGENCY USE ONLY (Leave blank) & $\begin{array}{c}\text { 2. REPORT DATE } \\
\text { October } 1993\end{array}$ & $\begin{array}{r}\text { 3. REPORT TYPE AND DATES COVERED } \\
\text { Technical Memorandum }\end{array}$ \\
\hline
\end{tabular}

4. TITLE AND SUBTTLE 5. FUNDING NUMBERS

Mixing Noise Reduction for Rectangular Supersonic Jets by Nozzle Shaping and Induced Screech Mixing

6. AUTHOR(S)

WU-537-02-22

Edward J. Rice and Ganesh Raman

7. PERFORIING ORGANIRATION MAME(S) AND ADDRESS(ES)

National Aeronautics and Space Administration

Lewis Research Center

Cleveland, Ohio 44135-3191

8. Pefforming organzation REPORT NUMBER

E-8165

9. SPONSORIMG/MONITORIMG AGENCY NAME(S) AND ADDRESS(ES)

National Aeronautics and Space Administration

Washington, D.C. 20546-0001

10. SPONSORINGMONTORING AGENCY REPORT NUMBER

NASA TM-106364

AIAA-93-4322

11. SUPPLEMENTARY MOTES

Prepared for the 15th AlAA Aeroacoustics Conference sponsored by the American Institute of Aeronautics and Astronautics, Long Beach, California, October 25-27, 1993. Edward J. Rice, Lewis Research Center and Ganesh Raman, Sverdrup Technology, Inc., Lewis Research Center Group, 2001 Aerospace Parkway, Brook Park, Ohio 44142 (work funded by NASA Contract NAS3-25266). Responsible person, Edward J. Rice, (216) 433-3607.

12a. DISTAIBUTRON/AVALABILTY STATEMENT 12b. DISTRIBUTION CODE

Unclassified - Unlimited

Subject Category 02

13. ABSTRACT (Maximum 200 words)

Two methods of mixing noise modification were studied for supersonic jets flowing from rectangular nozzles with an aspect ratio of about five and a small dimension of about $1.4 \mathrm{~cm}$. The first involves nozzle geometry variation using either single (unsymmetrical) or double bevelled (symmetrical) thirty degree cutbacks of the nozzle exit. Both converging $(C)$ and converging-diverging (C-D) versions were tested. The double bevelled C-D nozzle produced a jet mixing noise reduction of about $4 \mathrm{~dB}$ compared to a standard rectangular C-D nozzle. In addition all bevelled nozzles produced an upstream shift in peak mixing noise which is conducive to improved attenuation when the nozzle is used in an acoustically treated duct. A large increase in high frequency noise also occurred near the plane of the nozzle exit. Because of near normal incidence, this noise can be easily attenuated with wall treatment. The second approach uses paddles inserted on the edge of the two sides of the jet to induce screech and greatly enhance the jet mixing. Although screech and mixing noise levels are increased, the enhanced mixing moves the source locations upstream and may make an enclosed system more amenable to noise reduction using wall acoustic treatment.

14. SUBJECT TERMS

Jet mixing; Jet noise; Enhanced mixing; Induced screech; Edge tones; Rectangular jet; Converging-diverging nozzle

17. SECURITY CLASSIFICATION OF REPOAT Unclassified
18. SECURTY CLASSIFICATION OF THIS PAGE Unclassified
19. SECUATY CLASSIFICATION OF ABSTRACT Unclassified 